\title{
Recurrent Thyroid Gland Carcinoma
}

National Cancer Institute

\section{Source}

National Cancer Institute. Recurrent Thyroid Gland Carcinoma. NCI Thesaurus. Code C7908.

The reemergence of a thyroid gland carcinoma after a period of remission. 